\title{
ENTREVISTA COM RENÉ RAMÍREZ GALLEGOS, SECRETÁRIO DE EDUCAÇÃO SUPERIOR, CIÊNCIA E TECNOLOGIA DO EQUADOR DURANTE O PERÍODO DE 2011 A $2017^{1}$
}

\author{
ENTREVISTA CON RENÉ RAMÍREZ GALLEGOS, SECRETARIO DE EDUCACIÓN \\ SUPERIOR, CIENCIA, TECNOLOGÍA E INNOVACIÓN DEL ECUADOR DURANTE \\ EL PERÍODO 2011 A 2017
}

\author{
INTERVIEW WITH RENÉ RAMÍREZ GALLEGOS, SECRETARY OF HIGHER \\ EDUCATION, SCIENCE AND TECHNOLOGY OF ECUADOR DURING THE PERIOD \\ OF 2011 TO 2017
}

\author{
Gustavo MENON ${ }^{2}$
}

RESUMO: A seguinte entrevista foi realizada, em 2018, com o Secretário de Educação Superior, Ciência, Tecnologia e Inovação do Equador, durante o período de 2011 e 2017, René Ramírez Gallegos. Nela, René Ramírez faz um balanço do projeto que se autodenominou "Revolução Cidadã" (2007-2017), dirigido pelo presidente Rafael Correa e seu partido até então, a Alianza PAIS. Durante a entrevista, René Ramírez pontua os avanços do governo Correa e, acima de tudo, destaca as teses que vieram à tona durante a era correísta. A questão do buen vivir, a nova Constituição, o aumento dos investimentos na área da educação e a democratização do ensino superior são apenas alguns aspectos explanados pelo secretário. Ao mesmo tempo, René Ramírez Gallegos denuncia o projeto reacionário de "descorreização" em curso no país, que colocou fim às conquistas da chamada "década ganhada" no Equador.

PALAVRAS-CHAVE: Revolução cidadã. Equador. René Ramírez Gallegos.

RESUMEN: La siguiente entrevista se realizó en 2018 con el Secretario de Educación Superior, Ciencia, Tecnología e Innovación de Ecuador, durante el periodo 2011 y 2017, René Ramírez Gallegos. René Ramírez hace balance del proyecto que se llamó "Revolución Ciudadana" (2007-2017), dirigida por el presidente Rafael Correa y su partido hasta entonces, la Alianza PAIS. Durante la entrevista, René Ramírez señala los avances del gobierno de Correa y, sobre todo, destaca las tesis que salieron a la luz durante la era correísta. La cuestión del buen vivir, la nueva Constitución, el aumento de las inversiones en el área de la educación y la democratización de la educación superior son solo algunos aspectos explicados por el secretario. Al mismo tiempo, René Ramírez Gallegos denuncia el

\footnotetext{
${ }^{1}$ Essa entrevista fez parte da pesquisa de doutorado do autor. Para consulta da tese, ver: MENON, Gustavo. O projeto de extração de petróleo no Parque Yasuní na Amazônia equatoriana: a "Revolução Cidadã" entre o buen vivir e o neodesenvolvimentismo. 2019. Tese (Doutorado em Interunidades em Integração da América Latina Universidade de São Paulo, São Paulo, 2019.

${ }^{2}$ Faculdade de Guarulhos (FAG), Guarulhos - SP - Brasil. Docente na Faculdade de Guarulhos e no Centro Universitário SENAC - Santo Amaro. Pesquisador do Núcleo de Estudos de Ideologias e Lutas Sociais NEILS/PUC-SP. Doutor pelo (PROLAM-USP). ORCID: https://orcid.org/0000-0003-1057-027X. E-mail: gustavo22menon@gmail.com
}

RIAEE - Revista Ibero-Americana de Estudos em Educação, Araraquara, v. 15, n. 4, p. 2126-2145, out./dez. 2020. e-ISSN: $1982-5587$. DOI: https://doi.org/10.21723/riaee.v15i4.13815 
reaccionario proyecto de "descorreización" en curso en el país, que puso fin a los logros de la llamada "década ganada" en Ecuador.

PALABRAS CLAVE: Revolución ciudadana. Ecuador. René Ramírez Gallegos.

ABSTRACT: The following interview was conducted in 2018 with Ecuador's Secretary of Higher Education, Science, Technology and Innovation, during the period 2011 to 2017, René Ramirez Gallegos. René Ramirez takes stock of the project that called itself "Citizen Revolution" (2007-2017), conducted by the President Rafael Correa and his party until then, Alianza PAIS. During the interview, René Ramirez points out the progress of the Correa government and, above all, highlights the theses that came to light during the "correista" era. The issue of "buen vivir", the new Constitution, the increase in investments in the area of education and the democratization of higher education are just some aspects explained by the secretary. At the same time, René Ramirez Gallegos denounces the reactionary "descorreizacion" project underway in the country, which put an end to the achievements of the so-called "década ganada" in Ecuador.

KEYWORDS: Citizen revolution. Ecuador. René Ramírez Gallegos.

Descrição: Entrevista com René Alberto Ramírez Gallegos, economista e Secretário de Educação Superior, Ciência, Tecnologia e Inovação do Equador de 2011 a 2017.

Local da Entrevista: Quito - Equador.

Data: 26 de julho de 2018.

Formato: Gravada em formato mp3.

Tradução: Gustavo Menon e Guilherme Xavier.

Revisão: Mariane Bulegon - RIAEE 
Gustavo Menon - Estou investigando os planos nacionais para o Buen Vivir. Como que a Secretária Nacional de Planejamento e Desenvolvimento (SENPLADES) concebeu a introdução deste conceito? Observamos o Equador sendo um país dependente dos recursos do petróleo, sobretudo para a sua pauta de exportações, então, ao que me parece, há uma tentativa de redefinição das políticas com a ideia do Buen Vivir, como isso tem acontecido ao longo da última década no Equador?

René Gallegos - Perfeito.

Gustavo Menon - Então, esse é o primeiro ponto: como que o governo de Rafael Correa, na Constituição de Montecristi (2008), fez valer a ideia do Buen Vivir? Essa que é uma ideia originária dos povos indígenas que foi sendo construída com lutas antineoliberais na região da América do Sul como um todo. Então, queria que você falasse um pouco da construção do Buen Vivir no Equador...

René Gallegos - É um projeto político. Para ser um projeto político tem que ter orientações políticas dos rumos a serem seguidos pelos associados. Em 2006, nós respondemos a um programa do governo em que se vê o coração do antineoliberalismo. Nós sempre dissemos que uma Constituição antineoliberal implica em aspectos anticapitalistas. No entanto, um projeto jamais pode ser definido pela negação, mas sim pela afirmação. Temos que buscá-lo pelo o que ele tem que ser e não pelo “anti”, certo? É um debate muito interessante e há sempre o conceito do Buen Vivir que facilmente pode se ler muito mais minuciosamente na Constituição da República, onde realmente se estabelece a constituição da sociedade do buen vivir.

Gustavo Menon - Está completando 10 anos agora, certo?

René Gallegos - Sim, está completando justamente 10 anos e digo que existem 5 pontos de rupturas epistêmicas do modelo anterior. A primeira é a mudança de um antropocentrismo para o biocentrismo. A segunda alteração é passar de uma economia capitalista para uma economia social e solidária. A terceira é passar de um patriarcado para um feminismo. Um olhar feminino. A quarta é passar de um colonialismo para um Estado e sociedade 
plurinacional e intercultural. E a última é passar de uma democracia unicamente representativa para uma democracia participativa e deliberativa; então, o que nós dissemos foi uma questão de participação. Não podemos construir uma nova sociedade se o pacto de convivência segue sendo o mesmo que era em 1998, um pacto liberal-utilitário. Então, o primeiro que temos que fazer é um novo pacto de convivência e essas quebras que são estruturais surgem de lutas históricas aqui no Equador: do movimento indígena, do movimento dos trabalhadores de economia popular e solidária, das cooperativas, das mulheres, dos ambientalistas; a vontade de criar uma constituição é algo que te permite dar rumo ao sentido político e também te permite medidas de rupturas. $O$ fato é que o que tinha que ser feito era desmantelar toda a inconstitucionalidade, toda a política anterior e propor, mas isso é duro, creio que os 10 anos ainda não terminaram.

Gustavo Menon - Sim. Porque pelo que me parece em todas essas propostas há uma mudança de rumo político, uma mudança pautada no antineoliberalismo. Porque o neoliberalismo produzia efeitos nocivos de crises políticas e econômicas na sociedade equatoriana. Há um efeito perverso do neoliberalismo aqui no Equador, então acredito que, neste momento, vale a pena também comentar os caminhos do neoliberalismo que confluem para a dolarização.

René Gallegos - Os efeitos do neoliberalismo foram nefastos para o Equador, que chegaram ao ápice em 1999 e 2000, [quando] perdemos a soberania sobre a emissão do dinheiro. A economia decresceu sete pontos percentuais. A desigualdade e a pobreza aumentaram.

Gustavo Menon - A emigração também.

René Gallegos - Houve um processo de emigração, um pico emigratório incrível, houve muita precarização do emprego, as políticas sociais eram completamente subsidiarias para tratar de evitar qualquer tipo de processo de ingovernabilidade. Em termos políticos, houve sete presidentes em poucos anos, a desconfiança fazia parte dos partidos políticos e a sociedade civil era atroz.

Gustavo Menon - O presidente Correa chama isso de partidocracia, não é mesmo? 
René Gallegos - A partidocracia é tão profunda que nós chegamos com o discurso de "que se vayan todos!". A sociedade civil aplaudiu. Não porque dissemos "não participaremos das assembleias", porque isso seria uma inconstitucionalidade. O que nós vamos propor é uma nova constituição. O povo, ou seja, os velhos políticos diziam que o povo não entenderia uma nova constituição, como não vamos enviar candidatos ao Congresso Nacional. E não enviamos.

Gustavo Menon - E Correa aparece somente nas eleições de 2006?

René Gallegos - Sim. Passamos para o segundo turno contra Álvaro Noboa e imediatamente ganhamos as eleições. No primeiro decreto para a constituição [já] se convoca uma consulta popular que se intitula "uma Constituição". Elabora-se uma constituição em 2008 e se busca um referendo para aprovar a constituição, coisa que não foi feita em nenhuma constituição do Equador. Em 20 anos não houve uma Constituição do Equador que tenha sido aprovada, exposta ou referendada pela população. Apesar de um processo participativo brutal [na formatação] da Constituição, ela segue sendo lamentavelmente saqueada no presente momento. Voltando a ser um bruto fracasso e não um marco normativo social, porque está sendo violada...

Gustavo Menon - Atualmente a Constituição está sendo infringida?

René Gallegos - Está sendo desrespeitada, então, realmente volta a ser como antes. Bem, como em tempos anteriores. Perdemos. E o que se deve fazer é defender esta Constituição.

Gustavo Menon - E a participação dos movimentos sociais frente ao processo constituinte, como foi? Dos indígenas, das feministas, dos movimentos ambientalistas e sindicalistas?

René Gallegos - Sim, ou seja, houve um processo de debate e diálogo. [Houve uma grande] diferença porque a constituição a qual deixávamos para trás foi feita em um colégio militar, dizemos assim, fechada entre os legisladores. Esta foi feita em Manabí com uma participação 
incrível. Os próprios legisladores da Alianza PAIS vinham de movimentos sociais. Cada um com super indicações e propostas dos movimentos. Feministas, ambientalistas...

\section{Gustavo Menon - Professores?}

René Gallegos - Professores, estudantes... havia muitas propostas de constituição e tudo isso foi discutido, debatido e foi sendo atribuído sentido aos 444 artigos existentes. A minha pergunta é o que é o Buen Vivir, antes de mais nada? Às vezes há muita arrogância de certas pessoas sobre o conceito. É impossível de definir, eu diria. A Constituição obviamente inclui uma perspectiva indígena, mas o debate do Buen Vivir vai muito mais além também, porque há outros tipos de setores e olhares. No entanto, passamos a discutir o que antes não era discutido.

Gustavo Menon - Com a constituição de 2008 há um movimento de resgate da soberania do Equador, certo? Porque, por exemplo, a base de Manta foi fechada... mais que isso, há também uma orientação da política externa de aproximações com os países sul-americanos, cooperação sul-sul. É possível falar da política externa durante o processo da "Revolução Cidadã’?

René Gallegos - Todas essas mudanças podem ser definidas a partir da recuperação da soberania. Ou seja, o que nossos povos perderam é a soberania sobre o direito de decidir o que querem fazer com a história. E nós, o que fizemos foi recuperar isso. É impossível alcançar essa soberania sem passar por uma estratégia de integração. Essa também é uma necessidade social e econômica. Talvez para muitos países como o Brasil, a própria Argentina, eles não precisem de muita integração, porque eles têm um tamanho suficiente, organização suficiente, com uma estratégia interna própria. O Equador não representa nada no comércio internacional, político ou econômico. Queríamos que fosse uma iniciativa inteligente de integração partindo da UNASUL e da ALBA para definir instâncias regionais supranacionais, porque as [políticas] que existiam eram insuficientes para alcançar um bom papel nas discussões internacionais.

Gustavo Menon - E estavam sob o modelo neoliberal... 
René Gallegos - Completamente... a globalização do capital. Então, aí, a criação da ALBA, a criação da UNASUL, a proposta de criação do Banco do Sul, que infelizmente não prosperou. Teria sido outra história para a região, certo? Outra história. E obviamente, devemos seguir essa agenda porque não haverá soberania sem integração. Temos que ter uma estratégia de maior integração econômica, comercial e, obviamente, social e política.

Gustavo Menon - E também com esse novo modelo de significar a vida, acho que o Buen Vivir fala sobre isso, certo? Como nos comportamos frente à vida. Existe a iniciativa YasuníITT, que também passa pelo governo da "Revolução Cidadã" e em 2013 há um anúncio de que o parque terá que ser explorado e passar por medidas de exploração de petróleo. Como se deu esse processo de recuperação internacional que fracassou? Como que a extração desses recursos é importante para a economia equatoriana?

René Gallegos - O que tem que se entender aqui muito claramente é que o capitalismo, sob a minha perspectiva, tem que se fazer uma transição, e nessa transição você tem certas estratégias para colocar certos limites no capitalismo, certo? Enquanto você procura outro tipo, porque precisamos de alternativas para "desenvolvimentos", alternativas de desenvolvimento sustentável. Mas nessa transição há algumas questões que realmente colocam um freio no próprio capitalismo, e estas são as mudanças biofísicas, de tempo e de produção. A Yasuní-ITT se trata de levar, através de uma proposta limitada ao biofísico, [esse ponto] para a era dos combustíveis fósseis. Então, em termos práticos, é enfrentar o maior poder que existe no mundo, que tem a ver com as grandes multinacionais do petróleo. Então a probabilidade de que ela prosperasse como iniciativa era muito baixa. Há algumas declarações muito boas do Ministro da Cooperação da Alemanha que diz literalmente isto: "Não podemos deixar que prospere!". Seria algo nefasto para o mundo. O segundo ponto importante sobre isso é outro tipo de relacionamento. É uma mudança epistêmica, certo? Porque equivale ao que implica para a saúde, eu a chamo de passar da medicina tradicional para a prevenção da saúde, certo? Em termos ecológicos, certo? Isto é, me refiro que isso não implica em deixar de reduzir, mas sim evitar. É fazer um retorno à matriz epistêmica do capitalismo em si, certo? Então, entender que existem mais valores na vida do que no capital, do que em um barril de petróleo. É muito complicado, certo? Obviamente que este tópico parte da economia política que não podemos esperar. Além disso, a não compreensão do que estava em jogo, e a não 
compreensão de que aqui [deve ser feita] a valorização, porque aqui, eu nos faço essa pergunta, isto é, da esquerda, muitos falaram do conceito de valor de uso, a direita de valor de troca, mas o que realmente está em disputa é o conceito de valor em si. E o único que tem valor é a vida, certo? E isso é o que é incorporado na Constituição. Seguindo assim a perspectiva mais aristotélica, que é aquilo que tem valor em si mesmo, certo? E, obviamente, depois disso, o valor de uso tem que vir, mas vamos primeiro discutir o valor e mudar o senso comum. É mais importante a vida que o crescimento econômico, o crescimento monetário, o que for. Foi muito difícil entender e obviamente que em uma sociedade que tem muitas necessidades, há o custo de oportunidade que é muito alto, não é mesmo? Na verdade, eu acabei de colocar... esta semana, um tweet do próprio presidente, sabe? Que dizia que se não tivéssemos explorado esse momento, o Equador estaria quebrado. Então, é um assunto que nem beneficia o [ex]presidente. Ele assumiu todos os custos e praticamente nenhum benefício. Agora, penso que a questão da relação de custo de oportunidade talvez deva ser valorizada de maneira diferente, porque é um custo político-social muito alto também, certo? No sentido de que...

Gustavo Menon - O divórcio com parte dos movimentos sociais...

René Gallegos - Exatamente. Era muito simbólico, certo? Perdemos muito apoio...

Gustavo Menon - Desde a Lei da Mineração em 2009?

René Gallegos - Desde a Lei da Mineração em 2009 e bem... havia meses que perguntavam quais eram as reais opções políticas viáveis que permitiam disputar no sentido da transformação, ou seja, o importante é a transição, por isso que a chamo de grande transição, certo? Porque se alguém me diz: "bom, não vou explorar petróleo”, "bom, me diga de onde você tirará dinheiro, certo?" Ainda por cima sabendo que há indigências, existem muitas outras necessidades básicas insatisfeitas.

Gustavo Menon - De infraestrutura, de moradia, de bem-estar social, tudo isso, certo? 
René Gallegos - Tudo isso e ainda mais. É o que eu digo à esquerda, tem que entender que outra acumulação precisa de muito acúmulo de capital para fazer essa outra acumulação, ou nova acumulação, na transição. E isso a esquerda não gosta de ouvir, não é mesmo? Então, eles propõem projetos políticos que não são viáveis. Porque não há maneira de viabilizar o projeto político. E não é apenas uma questão de desejo, sabe? Quanto ao desejo, isto é, temos a Constituição.

Gustav Menon - É uma perspectiva materialista?

René Gallegos - Claro. Pós-materialista, porque eles não percebem que precisamos de materialidade agora para construir essa Constituição desse tipo de sociedade. E isso, às vezes, surge como se estivéssemos na Europa ou nos países nórdicos, quando há muitas necessidades não atendidas aqui.

Gustav Menon - E mais algumas perguntas, René. Porque, ao que também me parece, com a crise econômica de 2008, o processo da "Revolução Cidadã" foi severamente afetado. Por outro lado houve o boom das commodities. O preço do petróleo intensificou as exportações e agora os efeitos da crise estão chegando a grandes países da América do Sul e também nos demais países periféricos, como o Equador. Existe uma associação da crise de 2008 com a iniciativa de Yasuní? Da necessidade de explorar esse petróleo, esses recursos? Porque a partir daquele momento houve a necessidade de se acumular para promover políticas públicas, saúde, educação, tudo isso ...

René Gallegos -. Então, o ponto é, você diz: a Constituição diz que o petróleo é dos equatorianos, certo? Portanto, tenho que dizer a eles: "vocês, companhias petrolíferas, extraiam o petróleo, mas o petróleo é meu. Me digam o quanto me cobram e eu pago." Mas quando há uma mudança, tudo é perdido. Então, essa é uma questão primariamente com implicações de política energética, que em minha opinião teve uma perspectiva soberana na "Revolução Cidadã". Na semana passada, mais uma vez se voltou à antiga forma de contrato de petróleo, aqui. Esse é um ponto que tem a ver com isso, que tem que se decidir, um posicionamento único sobre o extrativismo para sair do extrativismo, entende? Então, você precisa exportar petróleo, sim ou não? Infelizmente a ideia da iniciativa não prosperou. Bem, 
façamos um pacto territorial, que é um pouco a proposta que fizemos. Se vamos explorar, vamos explorar lugares onde não há problema de conflito, de biodiversidade, de exploração. E mesmo assim, em algum momento da discussão, começaram a ser ditos quais são os lugares que não se deve explorar. Quer dizer, se há reservas, vou explorar? Eu preciso? Então, acho que foi esse ponto que justamente propusemos.

Gustav Menon - Na Constituição há também uma previsão de consulta frente às populações afetadas, certo?

René Gallegos - Tem que ter consulta. A consulta é feita, mas sem o caráter vinculante. Mas acredito que um pacto territorial deve ser feito, não é mesmo? Do meu ponto de vista, temos que fazer um pacto territorial, porque então podemos avançar para o relacionamento de política a nível mundial, entende? Então, esse é um segundo ponto no tema da política soberana. O segundo ponto é a questão desses recursos petrolíferos, onde se investe? E é também essa inversão que fizemos nessa jornada ao redirecionar para gerar as condições de outro tipo de acumulação. Obviamente isso não é feito em 10 anos ou menos. Eu acredito que houve totalmente 6,5 anos de governo em termos de políticas públicas e mudanças. Mas, o trabalho é feito visando toda a questão da energia limpa e da mudança na matriz energética.

Gustavo Menon - Essa mudança também aconteceu por um fortalecimento da Petroequador, [empresa pública de petróleo]?

René Gallegos - Petroequador e Petroamazonas. As companhias petrolíferas que não quiseram renegociar se foram e a Petroecuador assumiu, entende? Isso nos permitiu gerar os recursos para fazer toda a infraestrutura que foi feita, que tem a ver com a produtividade sistêmica, certo? Isto é, estradas, energia, saúde, educação, ensino superior, toda a questão de banda larga, o que realmente lhe dá uma outra perspectiva, de gerar outros tipos de condições para fazer. Há um assunto que para mim é bem estrutural que tem a ver com que discutimos muito com o próprio (ex)Presidente, ele nunca quis aceitar. É a questão da parte produtiva. Olhando além da estratégia... poderia ter duas estratégias, certo? Uma mudança na matriz produtiva do que existe ou a geração de novas indústrias que não mexe no que existe, mas que isso leva você a uma mudança lenta na matriz produtiva. O Equador foi para a segunda. Eu 
faço a exportação, que do meu ponto de vista é bom, certo? Porque você não pode estar contra todos, ou seja, na política você tem que ter um aliado, se focar muito intensamente na questão da rentabilidade do capital financeiro, creio que foi o principal, o vital, e agora se sofre as consequências justamente por um poder muito forte.

Gustavo Menon - Sim, com um processo de auditoria, da dívida...

René Gallegos - Exatamente. Mas onde não aconteceu e, para mim, tinha que chegar, porque afetaria os grupos econômicos mais estruturantes, bateu só praticamente nos últimos 2 anos em que os choques externos vieram, são os importadores. O problema não é ser exportador preliminar, mas sim o importador secundário. E o importador de terciário de conhecimento, certo? Importador secundário de manufatura e importador terciário de conhecimento. É isso que está gerando o problema estrutural que não conduz à mudança produtiva. E se uma mudança produtiva não é promovida, dificilmente vai ser possível a realização de uma mudança social. E essa foi uma questão central. De fato, a análise da política econômica dos Ministros do setor produtivo, do setor industrial, faz uma análise do comex, você vê por aí claramente a disputa da política econômica do Equador. Agora, pior, porque agora se está aliando na Aliança do Pacífico e assinando acordos comerciais como se a assinatura fosse uma piada, sabe? Então, condições estruturais estão sendo geradas que vão te levar ao abismo, entende? Ainda mais agora com a economia desorganizada.

Gustavo Menon - O processo de agravamento de dependência do Equador, certo?

René Gallegos - O processo de aumento da dependência é completamente contrário ao da soberania, certo?

Gustavo Menon - E também houve uma aproximação com o capital chinês?

René Gallegos - Houve uma aproximação do capital chinês, eu acho que aqui vale uma leitura regional. O Brasil não quis encabeçar a integração latino-americana. Que deste ponto de vista tinha que fazê-lo, certo? Começando com questões tão simples como o banco do Sul, ok? Nunca quis porque conflita com o banco BNDES, e, obviamente, isso afeta a própria 
integração, certo? E a China oferecia empréstimos que estavam indo para o investimento público, entende? Que era necessário. Em especial, na construção das hidroelétricas.

Gustavo Menon - Quantas hidrelétricas foram construídas nos últimos anos?

René Gallegos - 8 hidrelétricas e 1 eólica para a soberania energética.

Gustavo Menon - Sim. Agora o Equador é exportador de energia, não mais dependente.

René Gallegos - Não é mais dependente, por isso deveria fazê-lo, o melhor agora é investimento, ou seja, o melhor agora é ter uma sociedade saudável e educada, certo?

Gustavo Menon - É uma questão de soberania energética?

René Gallegos - É uma questão de soberania energética neste caso, certo? Eu vivi os tempos dos apagões quando eu era jovem, e quando começamos isso não havia as hidroelétricas, não havia soberania. Agora há, além de ser limpa. Quero dizer, são hidrelétricas, sabe? Então, o que houve neste caso, eu estava dizendo que a China tem a ver com não somente a questão do crédito, porque com isso me preocupo muito, mas também com a questão das relações de comércio que são estabelecidas, certo? Isso é um fenômeno da América Latina, entende? Se não me falha a memória posso provar, você pode ver os dados da América Latina. O grande problema é que 70\% das exportações de produtos primários vão para a China e mais de 90 dos bens secundários vêm da China. Então, a ascensão da classe média, ligada as compras de...

Gustavo Menon - De produtos chineses de valor agregado.

René Gallegos - De compras de produtos chineses, certo? Mas não com o capital que vai para o investimento. Há problemas de outra ordem. E há problemas estruturais.

Gustavo Menon - Com as indústrias nacionais... 
René Gallegos - É claro. Para mim, um assunto que não está recebendo a devida atenção e que às vezes fica empacado é a questão do crédito. Isso é importante, você tem que analisar bem as taxas e todas as discussões, mas, do meu ponto de vista, isso parece bem empregado em investimento público estratégico, porque foi principalmente em setores estratégicos e não vejo nenhum problema. A menos que haja problemas de qualidade, aí então não.

Gustavo Menon - E, no entanto, como parte dos movimentos sociais confrontou o governo de Rafael Correa, por chamar tais políticas de política neoextrativistas, o que eu quero perguntar é como os movimentos sociais também adotam um discurso conservador no que tange um antidesenvolvimento? Porque há, pelo que me parece, o CONAIE e outros movimentos que querem paralisar tudo, eles querem paralisar o processo de acumulação, que é importante para ser revertido em políticas públicas, como isso tem sido tratado nos últimos anos? Correa enfrentou essa oposição de forma sistemática? Como foi o divórcio com alguns desses movimentos sociais?

René Gallegos - Há uma questão que é necessária ser debatida. Essa passa pela troca de conhecimentos, ok? Nós, não importa como, acreditávamos que a mudança material, através da redistribuição, melhoraria as condições da sociedade, sabe? É realmente uma melhoria do bem-estar no Equador. Mas não em políticas de reconhecimento, especialmente relacionada ao movimento indígena, em minha perspectiva. Rafael [Correa] disse que a prioridade era a pobreza. Mas quando você tem que construir um Estado Plurinacional, não é suficiente atacar apenas a pobreza. É necessário também reconhecer que há uma diferença, que se trata de um país em que existem diferenças...

Gustavo Menon - De idiomas, de culturas...

René Gallegos - Nada disso, o tema pontual que você aponta é um tópico que é mais ideológico, por assim dizer. Porque não the dá alternativas, e não percebem que se faz esse investimento que irá beneficiar toda a sociedade, obviamente, também beneficiará aos indígenas... 
Gustavo Menon - Os mais pobres...

René Gallegos - Os mais pobres... Essa política colapsou muito rapidamente e vêm governos que são muito mais extrativistas, sabia? Assim como está acontecendo também agora na política de mineração, na política petrolífera, sem soberania, está entregando completamente tudo.

Gustavo Menon - Durante a "Revolução Cidadã" o que me parece de diferente é exploração do petróleo, conforme estava colocada nos anos 1990. Tivemos o escândalo do caso Chevron. Muita coisa mudou?

René Gallegos - As tecnologias utilizadas; a melhora dos campos realizada pela "Revolução Cidadã", [os novos projetos de extração] vai ganhando prêmios relacionados à eficiência energética...

\section{Gustavo Menon - Segurança?}

René Gallegos - Segurança, especialmente nos poços feitos pela Petroamazonas que tinham uma perspectiva hipersensível, como regulamentar a atuação petrolífera, certo? Então, o ponto é, mais uma vez, que você tem uma meta a ser alcançada. Mas parte com uma base que te apoiou, certo? Como você vai fazer? O debate para mim está nessa transição ecológica. Que é uma transição econômica. Então, não se trata só de uma questão energética, mas sim de toda a questão produtiva, vê? Geramos as condições, obviamente que isso, com a análise da política, análise de desenvolvimento a nível mundial, fica claro que os que mais rápido fizeram foi a Coréia e [ainda] foram algumas décadas, certo? Então, não se pode avaliar [um governo somente] por 10 anos. Pode-se falar, sim, de certas áreas, de certas políticas públicas, de certas áreas ou campos, setores econômicos, em que há muito mais cuidado... mas muito foi feito! Quando você vê o todo, claramente, o benefício, todo o investimento que foi feito, eu digo, não acontecerá novamente: foram como se fosse 100 anos, percebe? Em nenhum momento na história houve isso, pelo menos desde a democracia. Reduzimos a pobreza, reduzimos a desigualdade, diminuímos a polarização, melhorou a classe média, tanto em 
termos educacionais como subjetivos, sabe? Tudo isso é muito interessante e tem que ser analisado.

Gustavo Menon - A redução da indigência também...

René Gallegos - A redução da pobreza estrutural está ligada à garantia de direitos. Porque atacamos justamente essa materialidade, não é mesmo?! Para citar um exemplo: o ensino superior. É um direito conquistado. E o que nos interessava é a materialidade. A materialidade é a garantia de direitos neste caso, certo? E isso foi muito impressionante. 10 anos em que as carências diminuíram sistematicamente. Agora, durante o governo de Lenín Moreno, já existem indicadores que apontam o aumento da pobreza, o aumento da desigualdade e o aumento do emprego precarizado.

Gustavo Menon - Sim, porque há uma retomada da agenda neoliberal, certo?

René Gallegos - Completamente. Em outras palavras, uma agenda que é para favorecer as elites, a lei produtiva apresenta quase nenhuma redistribuição, é no melhor momento do neoliberalismo que pautas como essa agenda são apresentadas. A agenda do tráfego para os Estados Unidos, entende? E é uma perspectiva de que o livre comércio "é o melhor mecanismo de desenvolvimento." $\mathrm{E}$ já vivemos isso, há pontos que já foram vividos. $\mathrm{E}$ estamos repetindo os erros da dolarização novamente. Entramos em um processo de hiper acumulação dos grupos, especialmente, financeiros.

Gustavo Menon - É custosa a desdolarização, não é mesmo?

René Gallegos - Mais custosa que a entrada. Não tenho dúvidas, vê?! Então, foi preciso conviver com a dolarização e defender a dolarização, sabe?! Portanto, logicamente, supostamente dizem que a dolarização é a panaceia, [mas] tudo está acontecendo para que a dolarização caia. Chegamos assim a uma questão de responsabilidades históricas e neste caso temos a nossa consciência tranquila para dizer: "nós fizemos o que tínhamos que fazer", que era defender a dolarização em seu devido momento histórico, percebe? 
Gustavo Menon - Claro, claro. E, finalmente, René, a Constituição de Montecristi é eficaz em uma série de direitos. Os direitos da natureza, os direitos dos povos, os direitos coletivos, privados, dos grupos minoritários, os direitos das mulheres. Vale a pena recordar que o feminismo também foi protagonista no processo constituinte. No entanto, como foi o processo no campo da educação? Você foi ministro, houve a reafirmação de que a educação é um direito, especialmente o ensino superior. Como que isso se deu?

René Gallegos - A constituição faz menção à gratuidade e menciona que o ensino superior é um bem público sem fins lucrativos, ok?! Isso vinha sendo gerenciado no âmbito privado. Isso implicou em uma democratização no campo do ensino superior. Não é somente a mesma realidade para as mulheres, mas é um fenômeno que acontece com abrangência internacional, regional, a matrícula dos equatorianos mais pobres, dos indígenas, duplica, percebe?! O que acontece é a comparação entre os dez anos da "Revolução Cidadã" versus os outros dez anos de neoliberalismo para comparar períodos semelhantes. Ou seja, é algo muito interessante que tem a ver com o neoliberalismo nos 10 anos antes da Revolução Cidadã. $\mathrm{O}$ único extrato econômico que aumentou a renda foi o $30 \%$ mais rico, sabia? $\mathrm{Na} \mathrm{RC}$ o único que diminui é o $30 \%$ mais rico. Então, com isso, eu quero dizer que realmente [foi] um processo para que os apoiadores do neoliberalismo não crescessem. Houve o processo de democratização, e aí está uma questão que me preocupa, e que tem que ser agenda para os próximos processos da esquerda que tem que pensar a subjetividade, sabe? Trabalhamos com essa hipótese, a mudança na materialidade trouxe uma mudança da subjetividade. E é verdade. Mas o problema é que houve uma mudança na subjetividade pró-hegemônica ao invés de ser antihegemônica. E isso fez com que esses grupos que beneficiassem, entende? Isso anulou as possibilidades de ascensão do povo. E tem um espírito de classe, das classes superiores. Digo isso porque o conflito e a polarização decorrentes são porque quando você democratiza isso, obviamente, o campo da educação superior, isso incomoda. Entram pessoas que nunca tiveram acesso. Ou seja, garantimos pessoas que são a primeira geração de estudantes universitários em sua família. Isso mudou a vida de toda a sua família e da sua comunidade. E antes, quem já tinha isso garantido? Apenas uma classe econômica que buscava, no caso do ensino superior, um mecanismo simplesmente de distinção. Essas classes disseram sobre as universidades: "como estarei sentado com o trombadinha, com o índio, como sentarei com os pobres?" 
Gustavo Menon - Houve um processo de expansão das bolsas?

René Gallegos - Das bolsas?

Gustavo Menon - Sim, das bolsas.

René Gallegos - O aumento de bolsas de ensino, tanto a nível nacional como internacional, porque aí vem a outra questão em que sempre pensamos que uma mudança estrutural implica: colocar uma grande ênfase no campo cognitivo. No campo do conhecimento. E, por exemplo, os investimentos no ensino superior aumentaram de $1 \%$ para $2 \%$.

Gustavo Menon - De um a...?

René Gallegos - A 2\%. A América Latina nos últimos dez anos permaneceu em 0,8\%, 1\%. O Equador, com isso, não foi apenas o que mais cresceu, mas também o que tinha o nível mais alto em relação ao tamanho do seu PIB. Junto com a Bolívia que também teve um aumento significativo. Então essa questão foi deliberada. A recuperação do sistema de ensino superior como parte de uma estratégia de desenvolvimento de longo prazo. Obviamente que isso agora parece completamente interrompido, porque fica claro que existe uma estratégia de acumulação diferente da estratégia educacional. A estratégia de acumulação agora é a estratégia de acumulação do livre comércio [em] que a Universidade pública não é necessária, vai haver um...

Gustavo Menon - O que importa é o "Deus mercado", nada mais.

René Gallegos - Exatamente. E tenha em mente uma pessoa com doutorado que vai trabalhar em lojas para saber qual televisão é melhor em questão de tecnologia, mas é para vender produtos importados. Então, haverá um problema de expectativas. Porque as pessoas que estão estudando na América do Sul e Europa, nos Estados Unidos, nas melhores universidades em todo o mundo, que antes, isto é, era imaginável. Para comparar, veja, apenas nos últimos anos, antes da RC, o estado ofereceu 264 bolsas de graduação. Nós, em dez anos, oferecemos 
20.000 bolsas. Por quê? Porque as universidades precisavam melhorar, como parte de uma estratégia de desenvolvimento. Então, é isso, o único que as tinha era quem tinha a possibilidade de pagar por uma bolsa de estudos no exterior, porque conseguir bolsas para fora era muito complicado com os níveis educacionais que tínhamos aqui. E, obviamente, ver que antes que você não tinha voz e de repente começa a contradizer a pessoa que, há pouco tempo, era o mestre ou o chefe. Isso promove uma polarização social. Assim, em termos de educação, em termos educacionais, também foi brutal a mudança, todas as barreiras foram eliminadas na educação como um todo. Digo isso no que tangem aos direitos da educação. A renda, o uniforme, a comida, tudo era gratuito. Esse fenômeno que não é visto na América Latina. Uma aproximação do privado com o público. Porque o que acontece, normalmente, é uma aproximação do público com o privado. E, obviamente, aconteceu uma questão que é extremamente importante, que é estrutural, que é o assunto das expectativas. Se perguntados antes da "Revolução Cidadã", um em cada dez alunos queria seguir o ensino superior. Agora é um em cada dois. As expectativas de melhoria em ser ter uma educação foram brutais. E, claramente, também houve busca em termos de uma mudança epistemológica. As regras do regime acadêmico ditam que as universidades se repensem com base em certos tipos de princípios, como por exemplo: a interdisciplinaridade, a transdisciplinaridade, a interculturalidade. Temos que construir um Estado Plurinacional.

Gustavo Menon - E para não tomar mais do seu tempo, a Constituição também aprovou os direitos da natureza e para muitos juristas a Constituição de Montecristi é um mecanismo jurídico sofisticado, do ponto de vista dos direitos, das garantias e da natureza também, certo? Como a natureza é sujeito de direitos no Equador, como isso foi construído em um processo constituinte, como se dá essa inovação em termos da formulação dos direitos da natureza?

René Gallegos - Para mim, essa é uma das mudanças que eu diria ser não só epistêmica, mas também antológica da Constituição. Como eu te dizia, uma das primeiras mudanças era passar do antropocentrismo para o biocentrismo. Para as vidas, percebe? Não apenas dos humanos, mas de todas as espécies. Este é um tópico que tem sido muito trabalhado com os próprios movimentos ecológicos. É um assunto de muito debate na própria Constituição e que rompe com o paradigma liberal, [pois] não nos esqueçamos de que o paradigma liberal diz que somente alguns seres são dotados de direitos. 
Gustavo Menon - É uma visão de entender o ser humano como parte da natureza?

René Gallegos - Como parte da natureza, mas de uma perspectiva intergeracional, isto é, os meus filhos ou os meus netos devem ter os mesmos direitos à vida, à biodiversidade e aos direitos que nós temos. Os mesmos ou mais. É esta a ruptura, justamente...

Gustavo Menon - A água, por exemplo, como um direito e não como mercadoria.

René Gallegos - Claro, quero dizer, aí aparece a questão do biofísico também. Há um olhar do antropocentrismo ao ecocentrismo ou biocentrismo. Insisto em biocentrismo, porque é o centro da vida, não é mesmo? Sem vida, a terra, o ar, a água não fazem sentido. Mas, certamente, na economia política não se pode ver apenas o que dá a viabilidade para que a vida aconteça. E, obviamente, nisso a Constituição colocou a terra e a água como direitos, não como bens de consumo. Assim, há também o fator, da minha perspectiva, como muito mais inovações no estilo Yasuní. É um exemplo claro, é o melhor exemplo que se tem do que implica ter uma política como uma orientação de uma mudança epistêmica do que implica a sociedade do buen vivir. Então o ponto é a disputa política da transição como a sociedade é: eu os chamo de biosocialismo republicano ou o Socialismo de Sumak kawsay. Onde eles, obviamente, compõem os direitos da natureza, é um eixo fundamental que deve existir. Não pode conquistar a sociedade do buen vivir sem o respeito aos direitos da natureza. $\mathrm{Na}$ verdade, muda a tua visão de cidadania. Por quê? Porque a mudança na cidadania tem a ver com ser ao menos republicano, certo? Agora ecorepúblicano. Porque se temos o direito à natureza, temos uma obrigação para com a natureza. Eu tenho um dever, partindo de uma perspectiva unicamente liberal que se refere ao ter direitos, mas também deveres. Então, ao menos é uma mudança para uma cidadania eco-republicana, ok? Assim, o paradigma da, digamos, revolução social em direitos políticos implica outra democracia. Eu chamo de uma democracia humana sustentável. Porque...

Gustavo Menon - Um socialismo do sumak kawsay também? 
René Gallegos - Um socialismo do sumak kawsay, exatamente! E por que digo uma democracia humana sustentável? Porque neste momento a democracia representativa que coexiste com o capitalismo não é nem humana nem sustentável. Assim, este paradigma do socialismo Sumak kawsay implica uma mudança epistêmica que está além do capitalismo. E temos que ter uma agenda propositiva. E isso foi e é a Constituição. Agora, como poderíamos gerar um projeto de impacto da convivência social que transcende a ruptura e quando envolve outra antologia também, porque implica outra maneira de vê-la? Uma antologia própria. Que obviamente implica também em uma democracia experimental. Implica. Porque como as instituições que existem agora não vão decantar. Essa é a conclusão dessa sociedade, então é preciso imaginar que tipo de instituições que você precisa para esse socialismo do sumak kawsay.

Gustavo Menon - Muito obrigado, René.

\section{Como citar esta entrevista}

MENON, Gustavo. Entrevista com René Ramírez Gallegos, Secretário de Educação Superior, Ciência e Tecnologia do Equador durante o período de 2011 a 2017. Revista IberoAmericana de Estudos em Educação, Araraquara, v. 15, n. 4, p. 2126-2145, out./dez. 2020. e-ISSN: 1982-5587. DOI: https://doi.org/10.21723/riaee.v15i4.13815

Submetido em: 01/06/2020

Aprovado em: 25/06/2020

Publicado em: 30/08/2020 